\title{
Relationship between obstructive sleep apnea and markers of cardiovascular alterations in never-treated hypertensive patients
}

\author{
Aleksander Prejbisz ${ }^{1}$, Elżbieta Florczak ${ }^{1}$, Barbara Pregowska-Chwała ${ }^{1}$, Anna Klisiewicz ${ }^{2}$, \\ Beata Kuśmierczyk-Droszcz ${ }^{2}$, Tomasz Zieliński ${ }^{3}$, Magdalena Makowiecka-Cieśla ${ }^{1}$, Sylwia Kołodziejczyk-Kruk ${ }^{1}$, \\ Pawel Śliwiński ${ }^{4,5}$ and Andrzej Januszewicz ${ }^{1,5}$
}

We addressed a question if there is a relationship between severity of newly diagnosed obstructive sleep apnea (OSA) and markers of cardiovascular alterations in middle-aged untreated hypertensive patients. In 121 consecutive patients with never-treated essential hypertension (mean age $35.9 \pm 10.1$ years; 97 men and 24 women) evaluation of office and ambulatory blood pressure (BP) measurements, metabolic syndrome (MS) components and markers of alterations in cardiovascular system including left ventricular structure and function, carotid artery wall intima-media thickness (cIMT) and urinary albumin excretion (UAE) was performed. OSA was classified as mild (apnea/hypopnea index (AHI) 5-15 events $\mathrm{h}^{-1}$ ) or moderate-tosevere (AHI $>15$ events $\mathrm{h}^{-1}$ ). Mild and moderate-to-severe OSA were diagnosed in $30 \%$ and $20 \%$ of patients, respectively. No differences in nighttime BP levels and decline between patients with and without OSA were observed. The patients with moderate-to-severe OSA were characterized by higher cIMT ( $0.74 \pm 0.16$ vs. $0.60 \pm 0.15 \mathrm{~mm} ; P=0.001)$, UAE (14.5 \pm 6.9 vs.

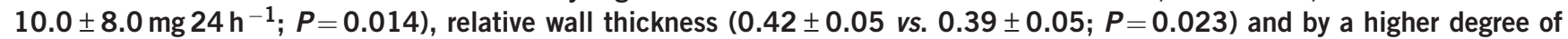
diastolic dysfunction ( $E^{\prime}$-wave velocity $11.4 \pm 3.2$ vs. $15.5 \pm 3.8 \mathrm{~m} \mathrm{~s}^{-1} ; P<0.001$ ) as compared with the patients without OSA. In multivariate analysis, AHI independently of BP and MS components correlated with UAE, relative wall thickness and $\mathrm{E}^{\prime}$-wave velocity. In the middle-aged never-treated hypertensive patients, moderate-to-severe OSA correlates with markers of cardiovascular alterations independently of BP levels and MS components.

Hypertension Research (2014) 37, 573-579; doi:10.1038/hr.2014.43; published online 13 March 2014

Keywords: albuminuria; carotid artery; heart; obstructive sleep apnea; subclinical organ damage

\section{INTRODUCTION}

There is growing evidence that obstructive sleep apnea (OSA) represents a major cardiovascular risk factor and is associated with increased cardiovascular and cerebrovascular morbidity and mortality. ${ }^{1,2}$

Recent studies have shown that the patients with OSA and hypertension are more likely to display signs of organ involvement-thickening of the carotid wall of the intima-media thickness (cIMT), left ventricular hypertrophy (LVH) and/or microalbuminuria. ${ }^{1-3}$ A major drawback of the studies done so far is that the role of OSA in these changes could not be established unequivocally. Most of the reports evaluating the association of OSA and hypertension with early atherosclerosis included patients with high burden of cardiovascular risk factors including established cardiovascular or cerebrovascular disease, severe obesity or diabetes, or patients receiving varied pharmacological therapy. ${ }^{1-3}$

However, the relationship between alterations in cardiovascular system and OSA has not been previously studied in middle-aged patients with never-treated hypertension without overt cardiovascular diseases. $^{1-4}$

The aim of our study was to evaluate the prevalence of newly diagnosed OSA in middle-aged patients with never-treated essential hypertension stages 1-2 without overt cardiovascular diseases. Moreover, we addressed the question if there is a relationship between the severity of newly diagnosed OSA and alterations in cardiovascular system. Therefore, we evaluated several signs of organ involvement including markers of left ventricular (LV) structure and function, carotid wall thickening and microalbuminuria.

\section{METHODS}

Study subjects

In years 2008-2010, 121 consecutive patients with never-treated essential hypertension, age 18-50 years, fulfilling inclusion criteria, attending the outpatient clinic of the Department of Hypertension, Institute of Cardiology, Warsaw, Poland, were asked to enter the study.

${ }^{1}$ Department of Hypertension, Institute of Cardiology, Warsaw, Poland; ${ }^{2}$ Department of Congenital Heart Diseases, Institute of Cardiology, Warsaw, Poland; ${ }^{3}$ Department of Heart Failure and Transplantation, Institute of Cardiology, Warsaw, Poland and ${ }^{4} \mathrm{~V}$ Department of Respiratory Medicine, Institute of Tuberculosis and Lung Diseases, Warsaw, Poland ${ }^{5} \mathrm{PS}$ and $\mathrm{AJ}$ are senior authors contributing equally to this work.

Correspondence: Dr A Prejbisz, Department of Hypertension, Institute of Cardiology, Alpejska 42, Warsaw 04-628, Poland. E-mail: a.prejbisz@ikard.pl

Received 22 July 2013; revised 11 November 2013; accepted 2 December 2013; published online 13 March 2014 
Before entering the study, clinical examination was performed to determine demographics, cardiac history, known duration of hypertension, cardiovascular risk factors and to exclude related comorbidities. Hypertension was diagnosed if office systolic and diastolic blood pressure (BP) levels were 140 and/or $90 \mathrm{~mm} \mathrm{Hg}$ or more and if the mean daytime ambulatory systolic BP and diastolic BP levels were higher than 130 and/or $85 \mathrm{~mm} \mathrm{Hg} .{ }^{5}$ Thus, patients with white-coat hypertension were not included into the study.

Subjects were excluded for any of the following reasons: secondary hypertension and/or related comorbidities including positive history or clinical signs of coronary heart disease, cerebrovascular disease, diabetes mellitus, previous treatment with the hypoglycemic, hypolipemiant and/or antihypertensive agents, neoplastic, hepatic or renal disease, estimated glomerular filtration ratio $<60 \mathrm{ml} \mathrm{min}^{-1}$ per $1.73 \mathrm{~m}^{2}$, disabling diseases or refusal to provide an informed consent.

\section{Study design}

The protocol included evaluation of: (1) office BP and ambulatory BP measurements, (2) sodium and potassium, lipids, blood count, fasting plasma glucose (FPG), creatinine and uric acid concentrations; (3) OSA: Epworth Sleepiness Scale and full night polysomnography and (4) markers of cardiovascular alterations in all patients. The study was approved by the Ethics Committee of the Institute of Cardiology, Warsaw, Poland and informed written consent was obtained from each patient.

\section{Measurements and definitions}

Anthropometric evaluations. All patients underwent standard clinical evaluation. Known duration of hypertension and neck and waist circumferences were recorded. Large neck circumference was defined as $\geqslant 41 \mathrm{~cm}$ or $\geqslant 43 \mathrm{~cm}$ for women and men, respectively. ${ }^{6}$ On the basis of weight and height, body mass index was calculated. Abdominal obesity was defined as a waist circumference $>102$ and $>88 \mathrm{~cm}$ for men and women, respectively. ${ }^{5}$ Current smoking, history of alcoholism, adrenergic medications and oral contraceptives were also documented.

Laboratory methods. Biochemical evaluation of blood samples taken after overnight fasting were determined by routine methods, and included sodium and potassium, lipids, blood count, FPG, creatinine and uric acid concentrations. Estimated glomerular filtration ratio was calculated using the Modification of Diet in Renal Disease formula. ${ }^{7}$ Glucose and lipid metabolism abnormalities as well as metabolic syndrome (MS) were diagnosed on the basis of the 2007 European Society of Hypertension/European Society of Cardiology (ESH/ESC) guidelines-normal FPG: $<5.6 \mathrm{mmoll}^{-1}$ and impaired FPG: 5.6-6.9 $\mathrm{mmoll}^{-1}$; increased low-density lipoprotein cholesterol concentration: $>3.0 \mathrm{mmoll}^{-1} .5$ For diagnosis of MS, three of five criteria had to be met: (1) BP $\geqslant 130 / \geqslant 85 \mathrm{~mm} \mathrm{Hg}$ - this criterion was met by all patients; (2) abdominal obesity as defined above; (3) high-density lipoprotein cholesterol male $<1.0 \mathrm{mmoll}^{-1}$, female $<1.2 \mathrm{mmoll}^{-1}$; (4) triglycerides $>1.7 \mathrm{mmoll}^{-1}$; and (5) $\mathrm{FPG} \geqslant 5.6 \mathrm{mmoll}^{-1.5}$

Office BP. Office BP was measured by a trained nurse with a patient in the sitting position after a 5-min rest, using an automated device (Omron 705IT, Omron, Kyoto, Japan). Three consecutive readings were performed at two separate visits. If the difference between readings was higher than $10 \mathrm{~mm} \mathrm{Hg}$, further measurements were taken so as to obtain three consecutive consistent readings at each visit. The average of these readings was recorded.

Ambulatory BP measurements. In all patients, ambulatory BP measurements were recorded using SpaceLabs 90207 or 90217 (Redmond, WA, USA) Readings were obtained every 15 min during the day (0600-2200 hours) and every $30 \mathrm{~min}$ during the night (2200-0600 hours). Differentiation between sleep and activity periods was made after recoding, based on data from the patient diary. Nocturnal decrease in BP was quantified as the relative decrease in nocturnal BP for both systolic and diastolic BP: ((daytime pressurenighttime pressure)/daytime pressure) $\times 100$ and expressed as a percentage. Subjects were classified as dippers if the proportional decrease from awake to asleep BP was $\geqslant 10 \%$.
Polysomnography. The Epworth Sleepiness Scale was evaluated before the sleep study. In all patients, data regarding mean sleep duration time and snoring were also assessed. The diagnosis of OSA was made by standard attended polysomnography with an Alice 5 (Respironics, Murrysville, PA, USA) device was performed in all subjects. The polysomnography recordings were scored manually using 30-s epochs following Rechtschaffen and Kales' criteria for sleep and wake determination and sleep staging. ${ }^{8}$ Abnormal respiratory events were evaluated according to standard criteria of the American Academy of Sleep Medicine Task Force. ${ }^{9}$

Apnea was defined as the absence of airflow for $\geqslant 10 \mathrm{~s}$. Hypopnea was scored if there was a $\geqslant 30 \%$ reduction in nasal pressure signal from baseline with a $\geqslant 4 \%$ desaturation for $\geqslant 10$ s. Hypopnea was also scored with $\geqslant 50 \%$ flow reduction associated with arousal. The apnea/hypopnea index (AHI) was the sum of apneas and hypopneas per hour of sleep. OSA was diagnosed as mild OSA (AHI 5-15 events $\mathrm{h}^{-1}$ ) or moderate-to-severe OSA (AHI > 15 events $\left.h^{-1}\right)$

\section{Assessment of cardiovascular alterations}

Carotid ultrasonography. The carotid ultrasound followed by a duplex color Doppler examination was done with a Phillips ATL 5000 (Philips, Eindhoven, The Netherlands) and a linear probe 7.5-12 MHz. Both left and right carotid arteries were analyzed. Multiple measurements on the distal wall from anterolateral and posterolateral longitudinal views were recorded. cIMT was measured at three points ( $3 \mathrm{~mm}$ apart) in two segments $1 \mathrm{~cm}$ from the flow divider caudally (carotid bulb) and $1 \mathrm{~cm}$ caudally from the beginning of the common carotid bulb (common carotid). The cIMT value was calculated as an arithmetical mean of 24 measurements from bulb and common carotid segments of both sides.

Echocardiography. Studies were performed with the use of a high-quality commercially available echocardiograph (Vivid 7, GE Healthcare, Little Chalfont, UK) equipped with $2.5 \mathrm{MHz}$ imaging transducer. End-diastolic LV diameter (LVEDd) and end-systolic LV diameter, interventricular septum thickness (IVSTd) and posterior wall thickness (PWTd) were calculated from two-dimensionally guided M-mode tracing from the parasternal long-axis view, in accordance with the American Society of Echocardiography recommendations. ${ }^{10} \mathrm{LV}$ mass was calculated from end-diastolic measurements using anatomically validated formula, ${ }^{11}$ and normalized by body surface area-LV mass index. LVH was defined when LV mass index was equal or exceeded $125 \mathrm{~g} \mathrm{~m}^{-2}$ in men and $110 \mathrm{~g} \mathrm{~m}^{-2}$ in women. Relative wall thickness (RWT) was calculated as the PWTd + IVSTd/LVEDd and indicated concentric LV geometry if at least 0.42 . LV systolic function was determined by the ejection fraction calculated in M-mode (Teicholz) at the parasternal long-axis and midwall fractional shortening. ${ }^{12}$ LV filling was assessed by recording mitral flow by standard pulsed Doppler technique with the sample volume placed at the tips of the mitral leaflets, from the apical four-chamber view. The following parameters were considered: peak early transmitral flow velocity (E), latediastolic flow velocity (A) and the ratio of the early to late peak (E/A ratio). The pulsed tissue Doppler imaging examination was performed from the apical four-chamber view, with the sample volume placed along the myocardial lateral wall and the left side of interventricular septum, $1 \mathrm{~cm}$ above the mitral annulus. Using the average of above two values, we measured myocardial earlydiastolic velocity $\left(E^{\prime}\right)$, end-diastolic velocity $\left(A^{\prime}\right)$ and their ratio $\left(E^{\prime} / A^{\prime}\right)$. We evaluated also $\mathrm{E} / \mathrm{E}^{\prime}$ ratio. Left atrial size was determined in the parasternal long-axis view as the maximal distance between the posterior aortic root wall and the posterior left atrial wall at end-systole and normalized by body surface area. All calculations were performed during three consecutive cycles.

Other. Urinary albumin excretion (UAE) was assessed using two 24-h urine collections (the average of two collections was recorded). Increased cIMT, LVH and microalbuminuria were defined according to ESH/ESC criteria. ${ }^{5}$

\section{Statistical analysis/analysis}

Data analysis was carried out using statistical software PASW Statistics 18 (SPSS, Chicago, IL, USA). The results are presented as mean \pm 1 s.d. or median and interquartile range. The values of variables between groups were 
compared-continuous and discrete variables: Mann-Whitney test or univariate analysis of variance with post-hoc Dunnett's $t$-test or T3 Dunnett's $t$-test depending on Levene's test of homogeneity of variances; categorical variables: $\chi^{2}$ test or Fisher's exact test. Parameters identified as statistically significant based on univariate analysis $(P<0.05)$ were included in the multivariate logistic or linear regression models in order to determine the combined effect of several variables on the incidence or value of the characteristic. $P<0.05$ was considered statistically significant.

\section{RESULTS}

We evaluated 121 consecutive patients with never-treated essential hypertension (mean age 35.9 \pm 10.1 years; 97 men and 24 women). Mild OSA was diagnosed in 36 patients $(29.8 \%)$ and moderateto-severe OSA in 24 patients (19.8\%). Polysomnography parameters are shown in the Supplementary Table 1. Patients with moderateto-severe OSA as compared with patients without OSA were characterized by higher frequency of MS and its components (Table 1).

Table 2 presents office BP and ambulatory BP measurement levels across the evaluated groups. Although generally patients with OSA were characterized by higher ambulatory systolic BP as compared with patients without OSA, the difference reached significance only for comparison between patients with mild OSA and without OSA (Table 2). No significant differences in BP profile between the groups were noted (Table 2 ).

Analysis was performed to determine the predictive value of the clinical variables associated with the moderate-to-severe OSA. Increasing age (odds ratio (OR) 2.00; $P=0.015$ for 10-year increase), large neck circumference (OR 3.34; $P=0.025$ ) and increased triglycerides levels (OR 3.07; $P=0.032$ ) but no other parameters including ambulatory BP measurement levels, nighttime BP decrease and Epworth Sleepiness Scale score predicted independently the presence of moderate-to-severe OSA (Supplementary Table 2). When in this model, components of MS were replaced by the presence of MS-it was the only variable significantly associated with the presence of moderate-to-severe OSA (OR 8.9; 95\% CI 3.0-26.2; $P<0.001$ ).

The overall frequency of established target organ damage was low-LVH, increased cIMT or carotid plaques and microalbuminuria were observed in $4 \%, 10 \%$ and $5 \%$ of patients, respectively. Patients with moderate-to-severe OSA but not with mild OSA were characterized by higher cIMT as compared with patients without OSA (Figure 1). There were significant correlations between AHI, mean saturation and minimal saturation and cIMT $(r=0.30 ; P=0.002$; $r=-0.23 ; P=0.014 ; r=-0.31 ; P<0.001$, respectively). However, in a multivariate model only age and decreased high-density lipoprotein were significantly and independently correlated with cIMT (Supplementary Table 3).

Patients with moderate-to-severe OSA but not patients with mild OSA were characterized by higher 24-h UAE as compared with patients without OSA $\left(14.5 \pm 6.9\right.$ vs. $10.0 \pm 8.0 \mathrm{mg} 24 \mathrm{~h}^{-1} ; P=0.014$ and $9.8 \pm 4.0$ vs. $10.0 \pm 8.0 \mathrm{mg} 24 \mathrm{~h}^{-1} ; P=0.99$, respectively). In a multivariate model, UAE was independently related with FPG and AHI (Supplementary Table 4).

Patients with moderate-to-severe OSA as compared with patients without OSA were characterized by higher indices of LV concentric remodeling as well as by worse indices of diastolic function (Table 3).

Table 1 Clinical characteristics of the studied patients

\begin{tabular}{|c|c|c|c|c|}
\hline & Patients without OSA & Patients with mild OSA & Patients with moderate-to-severe OSA & P-value \\
\hline Subjects $(n)$ & 61 & 36 & 24 & \\
\hline Men/women & $39 / 22$ & $36 / 0$ & $22 / 2$ & $<0.001$ \\
\hline Age (years) & $35 \pm 10$ & $35 \pm 10$ & $41 \pm 9 *$ & 0.019 \\
\hline Known duration of hypertension (years) & $1 \pm 1$ & $1 \pm 1$ & $1 \pm 1$ & 0.33 \\
\hline ESS points & $6(3.5-11.5)$ & $6(2.25-11)$ & $6.5(3-12)$ & 0.83 \\
\hline $\mathrm{BMI}\left(\mathrm{kg} \mathrm{m}^{-2}\right)$ & $26.1 \pm 4.0$ & $29.0 \pm 3.4^{\#}$ & $31.2 \pm 4.4^{\#}$ & $<0.001$ \\
\hline Large neck circumference (\%) & 25 & $50 *$ & $67^{\circ}$ & 0.001 \\
\hline Abdominal obesity (\%) & 31 & $53^{*}$ & $75^{\circ}$ & 0.001 \\
\hline Metabolic syndrome (\%) & 21 & $44^{*}$ & $79^{\circ}$ & $<0.001$ \\
\hline Smokers (\%) & $23.0 \%$ & $25.0 \%$ & $25.0 \%$ & 0.89 \\
\hline Sodium $\left(\mathrm{mmoll}^{-1}\right)$ & $141.3 \pm 1.9$ & $141.5 \pm 1.6$ & $142.3 \pm 2.1$ & 0.095 \\
\hline Potassium (mmoll-1) & $4.4 \pm 0.4$ & $4.4 \pm 0.4$ & $4.6 \pm 0.4$ & 0.056 \\
\hline Fasting glucose $\left(\mathrm{mmoll}^{-1}\right)$ & $5.3 \pm 0.6$ & $5.5 \pm 0.6$ & $6.3 \pm 2.3^{\#}$ & 0.004 \\
\hline Increased fasting glucose (\%) & 23 & 25 & $50 *$ & 0.039 \\
\hline Total cholesterol ( $\left.\mathrm{mmoll}^{-1}\right)$ & $4.9 \pm 1.0$ & $5.2 \pm 0.9$ & $5.4 \pm 1.0$ & 0.080 \\
\hline LDL cholesterol (mmoll-1) & $3.2 \pm 0.9$ & $3.4 \pm 1.0$ & $3.6 \pm 1.0$ & 0.18 \\
\hline HDL cholesterol (mmol $\left.\mathrm{I}^{-1}\right)$ & $1.5 \pm 0.4$ & $1.3 \pm 0.4$ & $1.2 \pm 0.3^{*}$ & 0.015 \\
\hline Decreased HDL level (\%) & 12 & 25 & $33^{*}$ & 0.049 \\
\hline Triglyceride $\left(\mathrm{mmoll}^{-1}\right)$ & $1.2 \pm 0.7$ & $2.0 \pm 1.6^{\#}$ & $2.3 \pm 1.8^{\#}$ & $<0.001$ \\
\hline Increased triglyceride level (\%) & 16 & $39 *$ & $63^{\circ}$ & $<0.001$ \\
\hline Creatinine level $\left(\mu \mathrm{mol} \mathrm{I}^{-1}\right)$ & $85.6 \pm 10.3$ & $82.8 \pm 10.7$ & $79.7 \pm 10.6$ & 0.100 \\
\hline eGFR ( $\mathrm{ml} \mathrm{min}^{-1}$ per $\left.1.73 \mathrm{~m}^{-2}\right)$ & $101.6 \pm 25.7$ & $99.8 \pm 15.6$ & $97.8 \pm 12.9$ & 0.77 \\
\hline Uric acid level ( $\left.\mu \mathrm{mol} \mathrm{I}^{-1}\right)$ & $314.8 \pm 80.9$ & $397.4 \pm 89.3$ & $382.5 \pm 69.3^{\#}$ & $<0.001$ \\
\hline
\end{tabular}

Abbreviations: BMI, body mass index; eGFR, estimated glomerular filtration ratio; ESS, Epworth Sleepiness Scale; HDL, high-density lipoprotein; LDL, low-density lipoprotein; OSA, obstructive sleep apnea.

Data are presented as mean \pm s.d. or as median (interquartile range) unless otherwise stated.

Large neck circumference: $\geqslant 41 \mathrm{~cm}$ female or $\geqslant 43 \mathrm{~cm}$ male. Abdominal obesity-waist circumference $>88 \mathrm{~cm}$ female or $>102 \mathrm{~cm}$ male. Increased fasting glucose concentration:

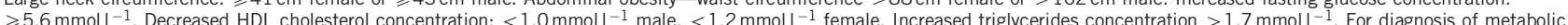

syndrome, three of five criteria had to be met: increased blood pressure-this criterion was met for all patients, abdominal obesity, increased fasting glucose, decreased HDL cholesterol

and increased triglyceride concentrations as defined above.

${ }^{*} P<0.05$; ${ }^{\#} P<0.01 ;{ }^{\oplus} P<0.001$ vs. patients without OSA, respectively. 
Table 2 Clinic and ambulatory blood pressure levels in relation to the presence of OSA and its severity

\begin{tabular}{|c|c|c|c|c|}
\hline & $\begin{array}{c}\text { Patients } \\
\text { without } \\
\text { OSA }\end{array}$ & $\begin{array}{c}\text { Patients } \\
\text { with mild } \\
\text { OSA }\end{array}$ & $\begin{array}{l}\text { Patients with } \\
\text { moderate-to- } \\
\text { severe OSA }\end{array}$ & P-value \\
\hline Subjects $(n)$ & 61 & 36 & 24 & \\
\hline Office SBP (mm Hg) & $145 \pm 9$ & $149 \pm 12$ & $147 \pm 9$ & 0.14 \\
\hline Office DBP (mm Hg) & $94 \pm 9$ & $96 \pm 13$ & $94 \pm 10$ & 0.68 \\
\hline Office heart rate (beats $\min ^{-1}$ ) & $84 \pm 16$ & $85 \pm 15$ & $83 \pm 10$ & 0.75 \\
\hline 24-h SBP (mm Hg) & $133 \pm 7$ & $138 \pm 8^{\#}$ & $136 \pm 7$ & 0.005 \\
\hline 24-h DBP (mm Hg) & $81 \pm 18$ & $84 \pm 10$ & $85 \pm 8$ & 0.046 \\
\hline 24-h heart rate (beats $\min ^{-1}$ ) & $76 \pm 9$ & $79 \pm 9$ & $79 \pm 9$ & 0.21 \\
\hline Daytime SBP (mm Hg) & $135 \pm 8$ & $140 \pm 9^{\#}$ & $140 \pm 8$ & 0.005 \\
\hline Daytime DBP $(\mathrm{mm} \mathrm{Hg})$ & $84 \pm 8$ & $87 \pm 10$ & $88 \pm 18$ & 0.098 \\
\hline Daytime heart rate (beats $\mathrm{min}^{-1}$ ) & $79 \pm 9$ & $81 \pm 10$ & $81 \pm 9$ & 0.34 \\
\hline Nighttime SBP (mm Hg) & $120 \pm 11$ & $124 \pm 10$ & $121 \pm 11$ & 0.058 \\
\hline Nighttime DBP (mm Hg)) & $70 \pm 9$ & $73 \pm 10$ & $72 \pm 10$ & 0.36 \\
\hline Nighttime heart rate (beats $\min ^{-1}$ ) & $65 \pm 8$ & $67 \pm 8$ & $69 \pm 9$ & 0.080 \\
\hline Nocturnal SBP decrease (\%) & $11 \pm 7$ & $11 \pm 6$ & $14 \pm 5$ & 0.14 \\
\hline Nocturnal DBP decrease (\%) & $17 \pm 8$ & $16 \pm 6$ & $19 \pm 7$ & 0.22 \\
\hline SBP dippers (\%) & $52 \%$ & $50 \%$ & $75 \%$ & 0.23 \\
\hline DBP dippers (\%) & $77 \%$ & $81 \%$ & $87.5 \%$ & 0.62 \\
\hline
\end{tabular}

Abbreviations: DBP, diastolic blood pressure; OSA, obstructive sleep apnea; SBP, systolic blood pressure.

Data are presented as mean \pm s.d. unless otherwise stated.

$\# P<0.01$ vs. patients without OSA, respectively.

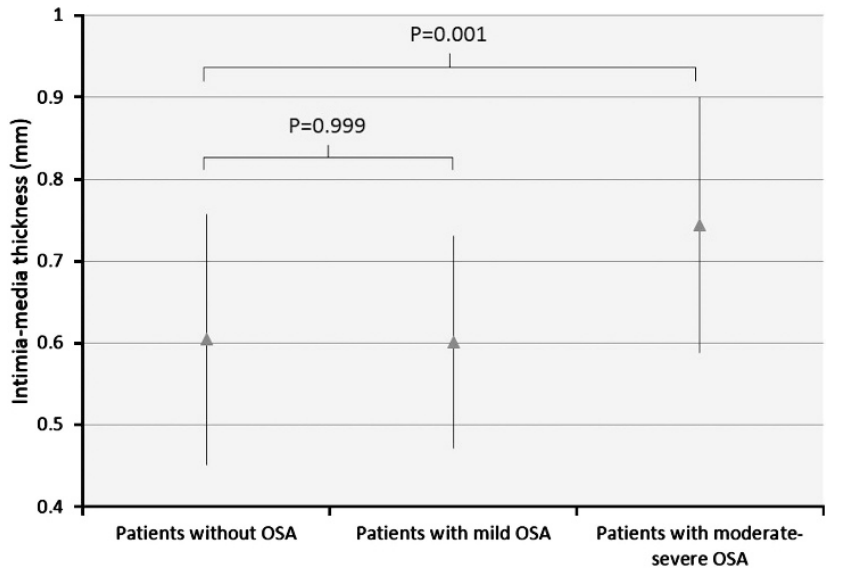

Figure 1 Carotid intima-media thickness according to the presence of obstructive sleep apnea (OSA) and its severity. The data are shown as mean value \pm 1 s.d.

There were no differences in parameters describing neither LV systolic function nor in LVM and LV mass index. In separate multivariate analysis, AHI correlated independently of other factors both with RWT and $\mathrm{E}^{\prime}$ (Table 4).

\section{DISCUSSION}

First, the novel finding of our study is to document high prevalence of newly diagnosed OSA in middle-aged patients with never-treated hypertension without overt cardiovascular diseases. However, it is difficult to compare our results with those from other studies as in most of them the prevalence of OSA was determined in patients with well-controlled hypertension or drug-resistant hypertension. ${ }^{3}$
Table 3 Echocardiographic parameters in relation to the presence of OSA and its severity

\begin{tabular}{|c|c|c|c|c|}
\hline & $\begin{array}{c}\text { Patients } \\
\text { without } \\
\text { OSA }\end{array}$ & $\begin{array}{c}\text { Patients } \\
\text { with mild } \\
\text { OSA }\end{array}$ & $\begin{array}{c}\text { Patients with } \\
\text { moderate- } \\
\text { to-severe OSA }\end{array}$ & $\mathrm{P}$-value \\
\hline Subjects $(n)$ & 61 & 36 & 24 & \\
\hline LVEDd (mm) & $49.8 \pm 4.6$ & $52.2 \pm 3.1 *$ & $50.9 \pm 5.1$ & 0.035 \\
\hline LVESd (mm) & $29.7 \pm 3.4$ & $31.8 \pm 5.4$ & $29.3 \pm 4.7$ & 0.244 \\
\hline IVSTd (mm) & $10.2 \pm 1.4$ & $10.6 \pm 0.8$ & $10.9 \pm 1.2^{*}$ & 0.058 \\
\hline PWTd (mm) & $9.7 \pm 1.2$ & $10.0 \pm 0.9$ & $10.6 \pm 1.2^{*}$ & 0.005 \\
\hline LAVI $\left(\mathrm{mm} \mathrm{m}^{-2}\right)$ & $1.8 \pm 0.3$ & $1.9 \pm 0.3$ & $1.8 \pm 0.2$ & 0.357 \\
\hline $\mathrm{EF}(\%)$ & $69 \pm 5$ & $69 \pm 6$ & $72 \pm 7$ & 0.084 \\
\hline mwFS (\%) & $18.5 \pm 1.9$ & $18.5 \pm 2.1$ & $18.2 \pm 1.7$ & 0.766 \\
\hline E wave $\left(\mathrm{cms}^{-1}\right)$ & $81 \pm 17$ & $75 \pm 19$ & $71 \pm 15$ & 0.084 \\
\hline A wave $\left(\mathrm{cms}^{-1}\right)$ & $63 \pm 22$ & $58 \pm 17$ & $65 \pm 14$ & 0.413 \\
\hline $\mathrm{E}^{\prime}$ wave $\left(\mathrm{cm} \mathrm{s}^{-1}\right)$ & $15.5 \pm 3.8$ & $14.1 \pm 3.1$ & $11.4 \pm 3.2$ & $<0.001$ \\
\hline $\mathrm{A}^{\prime}$ wave $\left(\mathrm{cm} \mathrm{s}^{-1}\right)$ & $9.5 \pm 2.6$ & $9.9 \pm 2.0$ & $10.0 \pm 2.0$ & 0.503 \\
\hline E/A ratio & $1.35 \pm 0.4$ & $1.4 \pm 0.5$ & $1.1 \pm 0.3^{*}$ & 0.053 \\
\hline$E^{\prime} / A^{\prime}$ ratio & $1.7 \pm 0.6$ & $1.5 \pm 0.6$ & $1.2 \pm 0.5^{\#}$ & 0.004 \\
\hline$E / E^{\prime}$ ratio & $5.4 \pm 1.4$ & $5.4 \pm 1.4$ & $6.3 \pm 1.3^{*}$ & 0.042 \\
\hline RWT & $0.39 \pm 0.05$ & $0.39 \pm 0.05$ & $0.42 \pm 0.05^{*}$ & 0.025 \\
\hline $\mathrm{RWT} \geqslant 0.42 \%$ & 32 & 22 & 50 & 0.08 \\
\hline LVM (g) & $184.3 \pm 40.1$ & $204.6 \pm 30.2^{*}$ & $209.8 \pm 45.8^{*}$ & 0.008 \\
\hline LVMI $\left(\mathrm{g} \mathrm{m}^{-2}\right)$ & $95.0 \pm 16.0$ & $98.2 \pm 13.7$ & $97.0 \pm 18.6$ & 0.62 \\
\hline
\end{tabular}

Abbreviations: A, late-diastolic flow velocity; $A^{\prime}$, tissue Doppler of end-diastolic ventricular filling velocity; $E$, early transmitral flow velocity; $E^{\prime}$, tissue Doppler of early-diastolic ventricular filling velocity; E/A ratio, ratio of early to late pulsed wave Doppler of diastolic ventricular filling; $E^{\prime} / A$ ratio, ratio of early to late tissue Doppler ventricular filling; $E / E^{\prime}$ ratio, ratio of earlydiastolic pulsed wave Doppler to early-diastolic tissue Doppler; EF, ejection fraction; IVSTd, interventricular septum thickness; LAVI, left atrial volume index; LVEDd, end-diastolic left ventricular diameter; LVESd, end-systolic left ventricular diameter; LVM, left ventricular mass; LVMI, left ventricular mass index; mwFS, midwall fractional shortening, OSA, obstructive sleep apnea; PWTd, posterior wall thickness; RWT, relative wall thickness.

Data are presented as mean \pm s.d. unless otherwise stated.

${ }^{*} P<0.05 ;{ }^{\#} P<0.01 ;{ }^{*} P<0.001$ vs. patients without OSA, respectively.

The non-dipping pattern of BP during the night has been reported as a feature of patients with OSA. ${ }^{3}$ However, in two recent studies, which included patients with resistant hypertension, no associations between higher nighttime BP levels nor nocturnal dipping pattern and the presence of OSA were reported. ${ }^{13,14}$ Our results also showed no differences in nighttime systolic BP and diastolic BP levels nor in BP nighttime decline between patients with OSA as compared with those without OSA. It is also of interest, that in contrast to some previous studies, blunted nocturnal dip was not correlated with the markers of cardiovascular alterations. Also, in a recent study involving a large group of middle-aged untreated hypertensive patients, Cuspidi et al. ${ }^{15,16}$ found that dippers have a similar subclinical cardiac and extra-cardiac organ damage as their nondipper counterparts.

Our study showed that the prevalence of MS was significantly higher in subjects with mild and moderate-to-severe OSA than in patients without OSA. We also found that the MS independently of other factors predicts the presence of moderate-to-severe OSA in hypertensive subjects. Our results support the concept that OSA is tightly linked to MS and represents an independent atherosclerotic burden in this population. ${ }^{17}$

Second, what is the novelty of our study, we examined whether there are echocardiographic differences between never-treated hypertensive patients with and without newly diagnosed OSA. Our results confirm this assumption, being in line with the findings of other studies reporting high prevalence of concentric hypertrophy or remodeling in population with hypertension and OSA. ${ }^{18-21}$ In fact, we documented only increased IVSTd and PWTd in patients with 
Table 4 Variables related with relative wall thickness (a) and $\mathrm{E}^{\prime}$-wave velocity (b) —univariate and multivariate linear regression analysis

\begin{tabular}{|c|c|c|c|c|}
\hline & \multicolumn{2}{|c|}{ Univariate model } & \multicolumn{2}{|c|}{ Multivariate model } \\
\hline & Beta & P-value & Beta & P-value \\
\hline \multicolumn{5}{|c|}{ (a) Variables related with relative wall thickness } \\
\hline Male gender & 0.043 & 0.65 & & \\
\hline Age 10 years increase & 0.087 & 0.35 & & \\
\hline $\mathrm{AHI}$ (events $\mathrm{h}^{-1}$ ) & 0.329 & $<0.001$ & 0.329 & $<0.001$ \\
\hline Fasting glucose $\left(\mathrm{mmol}^{-1}\right)$ & 0.194 & 0.054 & & \\
\hline Abdominal obesity & 0.242 & 0.009 & & \\
\hline 24-h SBP (mm Hg) & 0.012 & 0.90 & & \\
\hline 24-h DBP (mm Hg) & -0.030 & 0.75 & & \\
\hline Triglycerides $\left(\mathrm{mmoll}^{-1}\right)$ & 0.152 & 0.11 & & \\
\hline Decreased HDL cholesterol & 0.175 & 0.06 & & \\
\hline
\end{tabular}

(b) Variables related with $E^{\prime}$-wave velocity Male gender 0.023

Age (years) $\quad-0.558$

AHI (events $\mathrm{h}^{-1}$ ) $\quad-0.367$

Fasting glucose $\left(\mathrm{mmoll}^{-1}\right) \quad-0.355$

Abdominal obesity $\quad-0.200$

24-h SBP $(\mathrm{mm} \mathrm{Hg})$

24-h DBP $(\mathrm{mm} \mathrm{Hg}) \quad-0.012$

Triglycerides (mmoll-1 $\quad-0.189$

0.81

$<0.001$

$<0.001$

$-0.444$

$-0.223$

$<0.001$

$<0.001$

$-0.227$

0.013

0.039

0.34

0.90

0.055

Decreased HDL cholesterol

$-0.099$

0.31
Abbreviations: AHI, apnea/hypopnea index; DBP, diastolic blood pressure; HDL, high-density lipoprotein; SBP, systolic blood pressure.

Abdominal obesity - waist circumference $>88 \mathrm{~cm}$ female or $>102 \mathrm{~cm}$ male. Decreased HDL cholesterol: $<1.0 \mathrm{mmoll}^{-1}$ male, $<1.2 \mathrm{mmoll}^{-1}$ female. Only those variables that correlated significantly and were included in the multivariate model are shown in bold.

moderate-to-severe OSA as compared with patients without and with mild OSA. Our analyses also showed positive and independent association between RWT (index of LV geometry) and severity of OSA. Thus, in spite of normal LVM, these patients had a propensity to remodel ventricle in concentric geometry. The association between OSA and LV geometry have been previously investigated in studies conducted in patients with obesity and hypertension. ${ }^{21,22}$ Both overweight and increased BP determine a chronic LV overload and are two of the main factors leading to LVH. However, in our study abdominal obesity and BP levels were not related to RWT in the multivariate analysis, suggesting that severity of OSA had a more relevant effect on LV structure. This is in line with the findings of the study by Cioffi et al. ${ }^{23}$ which included 157 patients with suspected OSA undergoing polysomnography. The patients were older as compared with our study and comprised normotensive and both treated and untreated hypertensive subjects. It was also shown that moderate-to-severe OSA was related with increased RWT and concentric geometry independently of BP levels and obesity. The authors proposed that this phenomenon may be related to some consequences of severe OSA including significant hypoxemia, increased sympathetic drive and/or transmural pressure because of the respiratory effort during apneic/hypoapneic event.

In our study, systolic function assessed by ejection fraction was normal in all three groups. What more, midwall fractional shortening did not differ between study groups. It is in contrary to previous studies in which in hypertensive patients systolic shortening is often depressed. ${ }^{12,24}$ It may be explain by relatively normal thickness of LV wall and LV mass index in all three groups. However, diastolic function differed between study groups. In patients, without evidence of systolic left heart failure, we found a tendency toward diastolic dysfunction. In addition to this, myocardial diastolic function decreased with increasing OSA severity even so all the values were within what is thought to be the 'normal range'.

The previous studies on LV diastolic function in patients with hypertension and/or OSA have yielded conflicting results, ${ }^{25-32}$ depending on methodological approaches and selection of study population. Most studies have reported impaired diastolic function in patients with OSA. However, Niroumand et al. ${ }^{29}$ showed that OSA does not impair LV diastolic function in a large population. In this study, diastolic function was assessed only by conventional Doppler echocardiography (E/A ratio), which have limited value for making diagnosis of LV diastolic function. ${ }^{29}$

Tissue Doppler imaging-derived parameters seem to be more sensitive in detecting subtle changes in diastolic function in patients with OSA. ${ }^{27,28}$ The findings obtained in this study are in line with previous data obtained by tissue Doppler imaging in patients with essential hypertension ${ }^{26,30}$ or in general population. ${ }^{32}$ In an outpatient clinic, population conventional Doppler and tissue Doppler imaging demonstrated that patients with hypertension had an impaired LV relaxation and elevated LV end-diastolic pressure, expressed by the $\mathrm{E} / \mathrm{E}^{\prime}$ ratio. ${ }^{26}$ Wachter et al. ${ }^{32}$ in a cross-sectional cohort demonstrated that moderate-to-severe OSA was independently associated with impaired LV filling as assessed by comprehensive echocardiography including tissue Doppler. In our study, $\mathrm{E} / \mathrm{E}^{\prime}$ ratio was significantly higher in group with moderate-to-severe OSA comparing with group without OSA. Our results may bring hypothesis that the diastolic disturbances in these patients could likely be the cumulative burden of hypertension and sleep disturbance.

Third, this study showed that in middle-aged, never-treated hypertensive patients with newly diagnosed moderate-to-severe but not mild OSA, cIMT was significantly greater as compared with those without OSA. However, the range of cIMT values observed in most of our patients was below the currently accepted arbitrary cutoff point for increased cIMT. In contrast to our, in some other studies there was a significant difference in cIMT between those with mildly elevated AHI scores and the control groups. In most of the studies, cIMT was evaluated in normotensive subjects with OSA or in patients with OSA and hypertension who were older, had longer known duration of hypertension and were characterized by higher prevalence of target organ damage than those included in our study.

The impact of OSA and hypertension alone compared with the association of both conditions on markers of carotid atherosclerosis is not fully understood. Drager et al. ${ }^{33}$ showed that the association of OSA and hypertension has additive effects on markers of carotid atherosclerosis. The study showed that cIMT is positively related to systolic BP and AHI indicating that association between OSA and atherosclerosis could be mediated by the presence of hypertension. ${ }^{33}$

Silvestrini et al. ${ }^{34}$ were the first to demonstrate that male patients with severe OSA and without any symptoms of cardiovascular and cerebrovascular disease have an increased predisposition to carotid atherosclerosis, independent of the coexistence of the classic vascular risk factors.

It should be noted that our study differs in some ways from the previous reports. In only one study, Baguet et al. ${ }^{35}$ characterized cIMT and plaque occurrence in patients with newly diagnosed OSA and never-treated hypertension without known cardiovascular disease. In this group of 83 patients with moderate-to-severe OSA, mean cIMT was $0.67 \mathrm{~mm}, 30 \%$ of subjects had carotid wall hypertrophy and the significant relationship was found between cIMT and plaque 
formation and nocturnal oxygen desaturation. However, it is rather difficult to compare our study with those of Baguet et al. ${ }^{35}$ as in contrast to our group, the prevalence of untreated hypertension was $65 \%$ and the investigated patients were older.

In our study, a positive correlation was also found between AHI, mean saturation and minimal saturation and cIMT. However, in a multivariate model only age and decreased high-density lipoprotein cholesterol concentration were significantly and independently correlated with cIMT. Most of the studies have shown that cIMT is independently related to the severity of OSA, as expressed by AHI or nocturnal hypoxemia. It has been reported that not only severe OSA, but even mildly elevated AHI scores predispose to early atherosclerosis.

On the contrary, as in our study Kaynak et al. ${ }^{36}$ showed, that although cIMT values and the prevalence of plaque increased with respiratory disturbance index, cIMT was not significantly affected by the severity of OSA.

Fourth, hypertensive patients with moderate-to-severe newly diagnosed OSA but not patients with mild OSA were characterized by higher UAE as compared with patients without OSA. There was a significant correlation between $\mathrm{UAE}$ and $\mathrm{AHI}$, which remained significant in a multivariate model. This study showed that AHI correlated with UAE within the normoalbuminuric range.

Recent data indicate that the association of UAE with major cardiac events extends to urine albumin levels below the currently accepted arbitrary cutoff point for microalbuminuria. Our data are in agreement with the results of Ursavas et al., ${ }^{37}$ who reported that lowgrade UAE $\left(0-30 \mathrm{mg} \mathrm{g}^{-1}\right)$ was associated with OSA in normotensive/ non-diabetic patients, being independent of age and body mass index. In contrast to our study, subjects with hypertension were excluded from the study.

In another study, Tsioufis et al. ${ }^{38}$ performed in 62 untreated hypertensive patients with OSA, it was documented that UAE was increased within the normal range in hypertensive individuals with OSA as compared with those without OSA proportionally to OSA severity independently of confounders. Supporting our study, in a multivariate model AHI was an independent predictor of UAE. Our study and those of Tsioufis et al. ${ }^{38}$ may indicate that the association of upper-airway dysfunction with albumin excretion may provide an explanatory mechanism for the OSA-related risk in hypertension.

\section{Limitations}

We included only middle-aged or younger subjects with never-treated hypertension without a history of diabetes or cardiovascular disease, thus mitigating the potential confounding effects of age and comorbidities on our results. However, our results may not be applicable to the broader population of patients with hypertension.

The absence of a control group may be considered as a study limitation. However, it does not preclude the demonstration of an independent relationship between moderate-to-severe OSA and markers of alteration in cardiovascular system.

Finally, multivariate analysis can only describe the association, but not prove cause and effect. However, data from trials using continuous positive airway pressure in patients with OSA documented that waning of OSA can result in the improvement of markers of cardiovascular alterations.

\section{Summary}

In summary, our study documented relatively high prevalence of newly diagnosed OSA in middle-aged never-treated hypertensive subjects. High suspicion of OSA should be particularly raised in patients with MS. Our study showed a relatively low incidence of established subclinical organ damage. However, patients manifesting moderate-to-severe OSA were characterized by more pronounced markers of alterations in cardiovascular system. This relationship reflects predisposition of middle-aged hypertensive subjects with OSA to develop established target organ damage. It may be postulated that early recognition of OSA in patients with hypertension may prevent the development of organ damage, which reflects an intermediate stage in the continuum of cardiovascular disease and is a determinant of overall cardiovascular risk.

\section{ACKNOWLEDGEMENTS}

The study was supported by the scientific grant of the Institute of Cardiology no $2.45 / \mathrm{VII} / 08$

1 Kasai T, Floras JS, Bradley TD. Sleep apnea and cardiovascular disease: a bidirectional relationship. Circulation 2012; 126: 1495-1510.

2 Somers VK, White DP, Amin R, Abraham WT, Costa F, Culebras A, Daniels S, Floras JS Hunt CE, Olson LJ, Pickering TG, Russell R, Woo M, Young T. Sleep apnea and cardiovascular disease: an American Heart Association/American College Of Cardiology Foundation Scientific Statement from the American Heart Association Council for High Blood Pressure Research Professional Education Committee, Council on Clinica Cardiology, Stroke Council, and Council On Cardiovascular Nursing. In collaboration with the National Heart, Lung, and Blood Institute National Center on Sleep Disorders Research (National Institutes of Health). Circulation 2008; 118: 1080-1111.

3 Parati G, Lombardi C, Hedner J, Bonsignore MR, Grote L, Tkacova R, Levy P, Riha R, Bassetti C, Narkiewicz K, Mancia G, McNicholas WT. Position paper on the management of patients with obstructive sleep apnea and hypertension: joint recommendations by the European Society of Hypertension, by the European Respiratory Society and by the members of European COST (COoperation in Scientific and Technological research) ACTION B26 on obstructive sleep apnea. J Hypertens 2012; 30: 633-646.

4 Jozwik-Plebanek K, Prejbisz A, Janaszek-Sitkowska $H$, Klisiewicz A, Sliwinski $P$, Pregowska-Chwala B, Hoffman P, Januszewicz A. Obstructive sleep apnea and cardio-vascular damage. Kardiol Pol 2012; 70: 735-740.

5 Mancia G, De Backer G, Dominiczak A, Cifkova R, Fagard R, Germano G, Grassi G, Heagerty AM, Kjeldsen SE, Laurent S, Narkiewicz K, Ruilope L, Rynkiewicz A, Schmieder RE, Boudier HA, Zanchetti A. 2007 Guidelines for the Management of Arterial Hypertension: the task force for the management of arterial hypertension of the European Society of Hypertension (ESH) and of the European Society of Cardiology (ESC). J Hypertens 2007; 25: 1105-1187.

6 Davies RJ, Stradling JR. The relationship between neck circumference, radiographic pharyngeal anatomy, and the obstructive sleep apnoea syndrome. Eur Respir J 1990; 3: 509-514.

7 Levey AS, Coresh J, Greene T, Stevens LA, Zhang YL, Hendriksen S, Kusek JW, Van Lente F. Using standardized serum creatinine values in the modification of diet in renal disease study equation for estimating glomerular filtration rate. Ann Intern Med 2006; 145: 247-254.

8 Rechtschaffen A, Kales A. A Manual of Standardized Terminology, Technique and Scoring System from Sleep Stages of Human Subjects. US Department of Health, Education, and Welfare Public Health Service-NIH/NIND, Washington, DC, 1968.

9 Sleep-related breathing disorders in adults: recommendations for syndrome definition and measurement techniques in clinical research. The Report of an American Academy of Sleep Medicine Task Force. Sleep 1999; 22: 667-689.

10 Lang RM, Bierig M, Devereux RB, Flachskampf FA, Foster E, Pellikka PA, Picard MH, Roman MJ, Seward J, Shanewise JS, Solomon SD, Spencer KT, Sutton MS Stewart WJ. Recommendations for chamber quantification: a report from the American Society of Echocardiography's Guidelines and Standards Committee and the Chamber Quantification Writing Group, developed in conjunction with the European Association of Echocardiography, a branch of the European Society of Cardiology. J Am Soc Echocardiogr 2005; 18: 1440-1463.

11 Devereux RB, Lutas EM, Casale PN, Kligfield P, Eisenberg RR, Hammond IW, Miller $\mathrm{DH}$, Reis $\mathrm{G}$, Alderman $\mathrm{MH}$, Laragh JH. Standardization of M-mode echocardiographic left ventricular anatomic measurements. J Am Coll Cardiol 1984 4: $1222-1230$

12 de Simone G, Devereux RB, Roman MJ, Ganau A, Saba PS, Alderman MH, Laragh JH. Assessment of left ventricular function by the midwall fractional shortening/ end-systolic stress relation in human hypertension. J Am Coll Cardiol 1994; 23: 1444-1451.

13 Florczak E, Prejbisz A, Szwench-Pietrasz E, Sliwinski P, Bielen P, Klisiewicz A, Michalowska I, Warchol E, Januszewicz M, Kala M, Witkowski A, Wiecek A Narkiewicz K, Somers VK, Januszewicz A. Clinical characteristics of patients with resistant hypertension: the RESIST-POL study. J Hum Hypertens 2013; 27: 678-685.

14 Pedrosa RP, Drager LF, Gonzaga CC, Sousa MG, de Paula LK, Amaro AC, Amodeo C Bortolotto LA, Krieger EM, Bradley TD, Lorenzi-Filho G. Obstructive sleep apnea: the most common secondary cause of hypertension associated with resistant hypertension. Hypertension 2011; 58: 811-817. 
15 Cuspidi C, Macca G, Sampieri L, Fusi V, Severgnini B, Michev I, Salerno M, Magrini F, Zanchetti A. Target organ damage and non-dipping pattern defined by two sessions of ambulatory blood pressure monitoring in recently diagnosed essential hypertensive patients. J Hypertens 2001; 19: 1539-1545.

16 Cuspidi C, Sala C, Valerio C, Negri F, Mancia G. Nocturnal hypertension and organ damage in dippers and nondippers. Am J Hypertens 2012; 25: 869-875.

17 Coughlin SR, Mawdsley L, Mugarza JA, Calverley PM, Wilding JP. Obstructive sleep apnoea is independently associated with an increased prevalence of metabolic syndrome. Eur Heart J 2004; 25: 735-741.

18 Baguet JP, Barone-Rochette G, Tamisier R, Levy P, Pepin JL. Mechanisms of cardiac dysfunction in obstructive sleep apnea. Nat Rev Cardiol 2012; 9: 679-688.

19 Moro JA, Almenar L, Fernandez-Fabrellas E, Ponce S, Blanquer R, Salvador A. [Analysis of echocardiographic alterations observed in sleep apnea-hypopnea syndrome and how they are influenced by hypertension]. Rev Esp Cardiol 2008; 61. 49-57.

20 Moro JA, Almenar L, Fernandez-Fabrellas E, Ponce S, Blanquer R, Salvador A. Hypertension and sleep apnea-hypopnea syndrome: changes in echocardiographic abnormalities depending on the presence of hypertension and treatment with CPAP. Sleep Med 2009; 10: 344-352.

21 Noda A, Okada T, Yasuma F, Nakashima N, Yokota M. Cardiac hypertrophy in obstructive sleep apnea syndrome. Chest 1995; 107: 1538-1544.

22 Cloward TV, Walker JM, Farney RJ, Anderson JL. Left ventricular hypertrophy is a common echocardiographic abnormality in severe obstructive sleep apnea and reverses with nasal continuous positive airway pressure. Chest 2003; 124: 594-601.

23 Cioffi G, Russo TE, Stefenelli C, Selmi A, Furlanello F, Cramariuc D, Gerdts E, de Simone G. Severe obstructive sleep apnea elicits concentric left ventricular geometry. J Hyperten 2010; 28: 1074-1082.

24 Mayet J, Ariff B, Wasan B, Chapman N, Shahi M, Poulter NR, Sever PS, Foale RA, Thom SA. Improvement in midwall myocardial shortening with regression of left ventricular hypertrophy. Hypertension 2000; 36: 755-759.

25 Arias MA, Garcia-Rio F, Alonso-Fernandez A, Mediano O, Martinez I, Villamor J. Obstructive sleep apnea syndrome affects left ventricular diastolic function: effects of nasal continuous positive airway pressure in men. Circulation 2005; 112 : 375-383.

26 Bountioukos M, Schinkel AF, Bax JJ, Lampropoulos S, Poldermans D. The impact of hypertension on systolic and diastolic left ventricular function. A tissue Doppler echocardiographic study. Am Heart J 2006; 151: e1327-1312.
27 Haruki N, Takeuchi M, Nakai H, Kanazawa Y, Tsubota N, Shintome R, Lang RM, Otsuji Y. Overnight sleeping induced daily repetitive left ventricular systolic and diastolic dysfunction in obstructive sleep apnoea: quantitative assessment using tissue Doppler imaging. Eur J Echocardiogr 2009; 10: 769-775.

28 Kim SH, Cho GY, Shin C, Lim HE, Kim YH, Song WH, Shim WJ, Ahn JC. Impact of obstructive sleep apnea on left ventricular diastolic function. Am J Cardiol 2008; 101: 1663-1668.

29 Niroumand M, Kuperstein R, Sasson Z, Hanly PJ. Impact of obstructive sleep apnea on left ventricular mass and diastolic function. Am J Respir Crit Care Med 2001; 163: 1632-1636.

30 Pela G, Bruschi G, Cavatorta A, Manca C, Cabassi A, Borghetti A. Doppler tissue echocardiography: myocardial wall motion velocities in essential hypertension. Eur J Echocardiogr 2001; 2: 108-117.

31 Baguet JP, Barone-Rochette G, Levy P, Vautrin E, Pierre H, Ormezzano O, Pepin JL. Left ventricular diastolic dysfunction is linked to severity of obstructive sleep apnoea. Eur Respir J 2010; 36: 1323-1329.

32 Wachter R, Luthje L, Klemmstein D, Luers C, Stahrenberg R, Edelmann F, Holzendorf V, Hasenfuss G, Andreas S, Pieske B. Impact of obstructive sleep apnoea on diastolic function. Eur Respir J 2013; 41: 376-383.

33 Drager LF, Bortolotto LA, Krieger EM, Lorenzi-Filho G. Additive effects of obstructive sleep apnea and hypertension on early markers of carotid atherosclerosis. Hypertension 2009; 53: 64-69.

34 Silvestrini M, Rizzato B, Placidi F, Baruffaldi R, Bianconi A, Diomedi M. Carotid artery wall thickness in patients with obstructive sleep apnea syndrome. Stroke 2002; 33: 1782-1785.

35 Baguet JP, Hammer L, Levy P, Pierre H, Launois S, Mallion JM, Pepin JL. The severity of oxygen desaturation is predictive of carotid wall thickening and plaque occurrence. Chest 2005; 128: 3407-3412.

36 Kaynak D, Goksan B, Kaynak H, Degirmenci N, Daglioglu S. Is there a link between the severity of sleep-disordered breathing and atherosclerotic disease of the carotid arteries? Eur J Neurol 2003; 10: 487-493.

37 Ursavas A, Karadag M, Gullulu M, Demirdogen E, Coskun F, Onart S, Gozu RO. Low-grade urinary albumin excretion in normotensive/non-diabetic obstructive sleep apnea patients. Sleep Breath 2008; 12: 217-222.

38 Tsioufis C, Thomopoulos C, Dimitriadis K, Amfilochiou A, Tsiachris D, Selima M, Petras D, Kallikazaros I, Stefanadis C. Association of obstructive sleep apnea with urinary albumin excretion in essential hypertension: a cross-sectional study. Am J Kidney Dis 2008; 52: 285-293.

Supplementary Information accompanies the paper on Hypertension Research website (http://www.nature.com/hr) 